\title{
Solitary caecal diverticulitis as an unusual cause of a right iliac fossa mass: a case report Mohamed A Kurer
}

\author{
Address: Department of General Surgery, Colorectal Unit, York Hospital, York, YO31 8HE, UK
}

Email: Mohamed A Kurer - mohamed.kurer@york.nhs.uk

\begin{abstract}
Published: 10 November 2007
Received: 12 June 2007

Journal of Medical Case Reports 2007, I:132 doi:10.1 186/1752-1947-1-132

Accepted: 10 November 2007

This article is available from: http://www.jmedicalcasereports.com/content/l////32

(c) 2007 Kurer; licensee BioMed Central Ltd.

This is an Open Access article distributed under the terms of the Creative Commons Attribution License (http://creativecommons.org/licenses/by/2.0), which permits unrestricted use, distribution, and reproduction in any medium, provided the original work is properly cited.
\end{abstract}

\begin{abstract}
Inflammation of a solitary caecal diverticulum is an uncommon pathological condition. Preoperatively the condition is almost indistinguishable from appendicitis, and is often confused with carcinoma of the caecum during operation. The typical patient with this condition is male, Asian, and in the fourth decade of life. This case is unusual in that the patient was a 26-year-old Caucasian man.
\end{abstract}

\section{Case presentation}

A 26-year-old white man was admitted to our hospital with a three day history of constant abdominal pain, which started centrally and shifted to the right lower quadrant. He had had recurrent episodes of abdominal pain for six months prior to his presentation. He had no vomiting or change of bowel habit, and no urinary symptoms. Physical examination revealed a temperature of $37.9^{\circ} \mathrm{C}$, pulse 90 beats $/ \mathrm{min}$, and $\mathrm{BP} 130 / 80 \mathrm{mmHg}$. Marked right iliac fossa tenderness with rebound was the only significant physical finding. Digital rectal examination was normal. Apart from a raised WCC of 12.9 and CRP of 42 , other initial investigations including urinalysis where within normal limits.

A presumptive diagnosis of appendicitis was made. Laparotomy revealed a right iliac fossa mass. There was a small amount of clear free fluid. The appendix was normal, as was the terminal ileum. There was a solitary diverticulum projecting from the medial aspect of the caecum and forming an inflammatory mass with the omentum. A limited right hemicolectomy was performed. The patient's recovery was uneventful. Examination of the resected specimen showed solitary caecal diverticulitis with perforation.

\section{Discussion}

The first case of a solitary caecal diverticulum was reported in 1863; more than 500 cases have been recorded since then. The condition is uncommon, seen in only 10 of 5,000 radiological examinations, with greater incidence in Oriental people [1]. This condition is unrelated to the common and well known multiple colonic diverticular disease which is a common disorder in the West. According to experience in Singapore, the average age of presentation of caecal diverticulitis is 36 years (3-74) with male predominance [2]. Nearly $80 \%$ of caecal diverticula are situated in the area from one $\mathrm{cm}$ proximal to two cm distal to the ileocaecal valve [3]. They are usually solitary. Approximately $60 \%$ of solitary caecal diverticula arise from the anterior aspect of the caecum, so when inflamed they tend to perforate and cause peritonitis. However, a posteriorly situated caecal diverticulum may produce a mass without generalized peritonitis, simulating perforating carcinoma. Correct preoperative diagnosis of acute caecal diverticulitis is made only in about $9 \%$ of the patients, and most of these patients have had previous 
appendicectomy. Even peroperatively, the correct diagnosis is only made in about $65 \%$ of cases [4]. Although the aetiology of a solitary caecal diverticulum is uncertain, congenital origin is widely accepted. The theory is that an outgrowth of the caecum develops in the sixth week and atrophies by about the seventh week. If this 'transient appendix' fails to disappear, a diverticulum or a duplication of the appendix results [5-7]. This concept is supported by the fact that the condition has been reported in a 3-year-old girl [8], the incidence does not increase with age [9], and it is a true type of diverticulum. Most authors agree that, preoperatively, it is almost impossible to distinguish between acute solitary caecal diverticulitis and acute appendicitis, even retrospectively [10]. However, some authors believe that the longer duration of illness $[11]$, the absence of nausea and vomiting [3], and the relative lack of toxicity [12], are features of caecal diverticulitis.

It has been suggested that chronic recurrent abdominal pain due to inflammation of a solitary caecal diverticulum might be responsible for the syndrome of "grumbling appendix". The outcome of chronic recurrent abdominal pain has been studied by many surgeons as well as gynaecologists often using laparoscopy. Caecal diverticula have not been encountered as a cause of the chronic recurrent abdominal pain. Adhesions, chronic and acute appendicitis, inguinal hernia, and endometriosis are the main causes of chronic recurrent abdominal pain [13].

There is no standard surgical procedure for the treatment of an inflamed solitary caecal diverticulum. The extent of the inflammation, the experience of the surgeon, and the confidence in the intraoperative diagnosis determine the procedure. Procedures range from simple diverticulectomy to right colectomy, with appendicectomy when only the diverticulum is removed [1]. Management of an incidentally found solitary caecal diverticulum is more controversial. The condition may be encountered preoperatively, e.g. following a barium enema examination, in which case it is probably sensible to do nothing. Whether to interfere or not, in the case of an asymptomatic solitary caecal diverticulum, should be based on the chances of it becoming inflamed or developing other complications. Although Canver and Freier claimed that $14 \%$ of caecal diverticula will ultimately become inflamed [14], they did not make it clear how they came to this conclusion. Perhaps the more important question is what we should do if a solitary caecal diverticulum is found incidentally at laparotomy. Langdon advised either excision or inversion [15]. However, because the problem is uncommon this approach is not evidence-based.

This case report illustrates the importance of being aware of solitary caecal diverticulitis as a differential diagnosis of a patient with a right iliac fossa mass presenting with acute abdominal pain. Simple diverticulectomy with appendicectomy may be adequate if the diagnosis is made with confidence. Right hemicolectomy is advisable if the diagnosis is uncertain or the inflammation is extensive.

\section{Conclusion}

An acutely inflamed solitary caecal diverticulum is an uncommon cause of an acute abdomen in the western population. Clinically it is almost indistinguishable from acute appendicitis. The condition may present with a right iliac fossa mass and is likely to present a diagnostic challenge when encountered peroperatively, particularly to the trainee surgeons who are likely to be dealing with such cases. Although there are many treatment options, in the event of peroperative diagnostic uncertainty and in particular when neoplasia and granulomatous diseases can not be ruled out, a limited right hemicolectomy is advisable.

\section{Competing interests}

The author(s) declare that they have no competing interests.

\section{Authors' contributions}

MK managed the case and wrote the manuscript.

\section{Acknowledgements}

Written informed consent was obtained from the patient for publication of this case report.

\section{References}

I. Williams KL: Acute solitary ulcers and acute diverticulitis of the caecum and ascending colon. BrJ Surg 1960, 47:35I-358.

2. Tam EC, Tung KH, Wee A: Diverticulitis of caecum and ascending colon in Singapore. J R Coll Surg Edinb 1984, 29:373-376.

3. Lauredsen J, Ross FP: Acute diverticulitis of caecum. Report of 4 cases and review of 153 surgical cases. AMA Arch Surg 1952, 64:320-330.

4. Wuble EJ, Lee WC: Caecal diverticulitis changing trends in management. South Med J 1988, 81:313-316.

5. Gladstone RJ, Wakeley CPG: The relative frequency of the various positions of the vermiform appendix; as ascertained by an analysis of 3000 cases: with an account of its development. Br J Surg 1924, I I:503-520.

6. Cave AJE: Appendix vermiformis duplex. J Anat 1936, 70:283-292.

7. Waugh TR: Appendix vermiformis duplex. Arch Surg 194I, 42:3II-320.

8. Odqvist $B$, Petren T: Ein Fall von angeborener Divertikelbildung des Blinddarms. Virchows Arch [Pathol Anat] 1931, 280:58I-586.

9. Hughes LE: Post-mortem survey of diverticulum disease of the colon. I: diverticulosis and diverticulitis. Gut 1969, 10:336-344.

10. Laimon H, Cohn P: Diverticulitis of the caecum. A report of eight cases. Am J Surg 1962, 103:146-149.

II. Rigler RG, Cherry JW: Diverticulitis of the caecum. Preoperative diagnosis. Am Surg 1960, 26:405-408.

12. Anscombe AR, Keddie NC, Schofield PF: Solitary ulcers and Diverticulitis of the caecum. BrJ Surg 1967, 54:553-557.

13. Miller K, Mayer E, Moritz E: The role of laparoscopy in chronic recurrent abdominal pain. Am J Surg 1996, I72:353-7.

14. Canver C, Freier T: Management of cecal diverticulitis. Am J Gastroentrol 1 986, 8 1: I 1 04- I 106.

15. Langdon A: Solitary diverticulitis of the right colon. Can J Surg 1982, 25:579-58I. 